\title{
FATIGUE LIFE ESTIMATION OF REAR FUSELAGE STRUCTURE OF
} AN AIRCRAFT

\author{
Chetan B S $\mathbf{S}^{1}$, Narayana Swamy $\mathbf{G}^{2}$, K E Girish ${ }^{3}$ \\ ${ }^{l}$ Department of Computer Aided Engineering, Visvesvaraya Institute of Advanced Technology, Karnataka, India \\ ${ }^{2}$ Department of Computer Aided Engineering, Visvesvaraya Institute of Advanced Technology, Karnataka, India \\ ${ }^{3}$ Bangalore Aircraft Industries, Karnataka, India
}

\begin{abstract}
Integrity of the airframe structure is achieved through rigorous design calculations, stress analysis and structural testing. Finite element method (FEM) is widely used for stress analysis of structural components. Each component in the airframe becomes critical based on the load distribution, which in-turn depends on the attitude of the aircraft during flight. Fuselage and wing are the two major components in the airframe structure. The current study includes a portion of the fuselage structure. Empennage is the rear portion of the aircraft, which consists of rear fuselage, Horizontal tail and vertical tail. The air loads acting on the HT also get transferred to rear portion of the fuselage. First step in ensuring the safety of the structure is the identification of critical locations for crack initiation. This can be achieved through detailed stress analysis of the airframe In this project one of the major stress concentration areas in the fuselage is considered for the analysis. Rear fuselage portion with a cargo door cutout region will be analysed. The structure considered for the stress analysis consists of skin, bulkheads and longerons, which are connected to each other through rivets. Aerodynamic load acting on the aircraft components is a distributed load. Depending on the mass distribution of the fuselage structure the inertia forces will vary along the length of the fuselage. The inertia force distribution makes the fuselage to bend about wing axis. During upward bending, bottom portion of the fuselage will experience tensile stress. A cutout region in the tensile stress field will experience high stress due to concentration effect. These high stress regions will be probable fatigue crack initiation locations in the current work, fatigue damage calculation will be carried out to estimate the fatigue life of the structure under the fluctuating loads experienced during flight. Miner's rule will be adopted for fatigue damage calculation.
\end{abstract}

Keywords: Transport aircraft, Rear fuselage, Cargo door, Finite element method, Stress concentration, Fatigue damage, Miner' rule

\section{INTRODUCTION}

An aircraft is a machine that is able to fly by gaining support from the air, or, in general, the atmosphere of a planet.

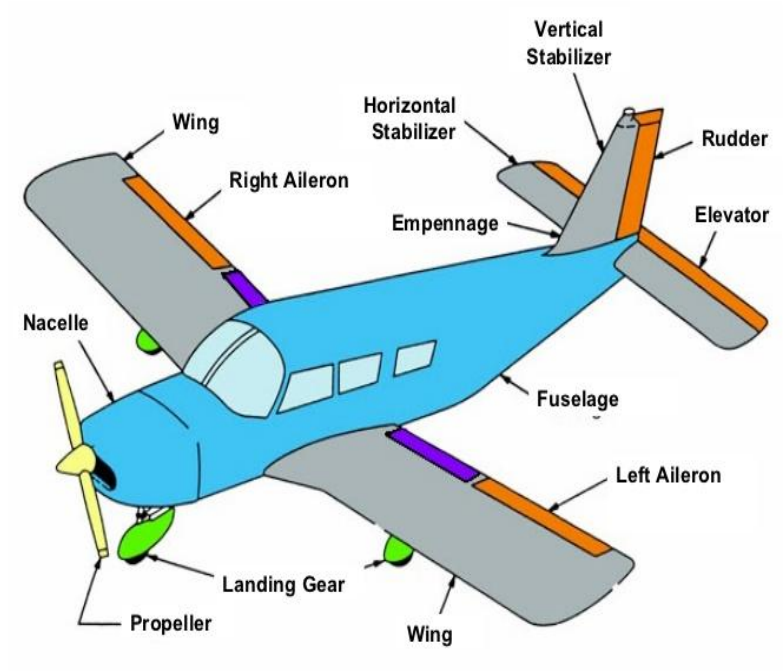

\subsection{Major parts of aircraft}

$\begin{array}{ll}1 & \text { Fuselage } \\ 2 & \text { Empennage } \\ 3 & \text { Wing } \\ 4 & \text { Landing gears }\end{array}$

\subsection{Fuselage}

The main body structure is the fuselage to which all other components are attached. The fuselage contains the cockpit or flight deck, passenger compartment and cargo compartment. There are two general types of fuselage construction: truss and monocoque.

\subsubsection{Truss Type}

A truss is a rigid framework made up of members, such as beams, struts, and bars to resist deformation by applied loads.

Fig-1: Aircraft structure 


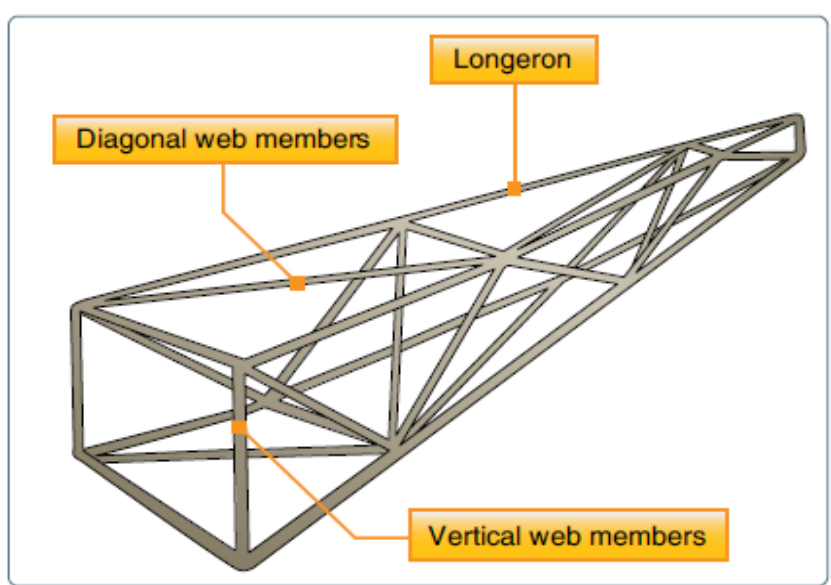

Fig-2: A truss-type fuselage. A Warren truss uses mostly Diagonal bracing.

\subsubsection{Monocoque Type}

The monocoque (single shell) fuselage relies largely on the strength of the skin or covering to carry the primary loads. The design may be divided into two classes:

\subsubsection{Monocoque}

The true monocoque construction uses formers, frame assemblies, and bulkheads to give shape to the fuselage.

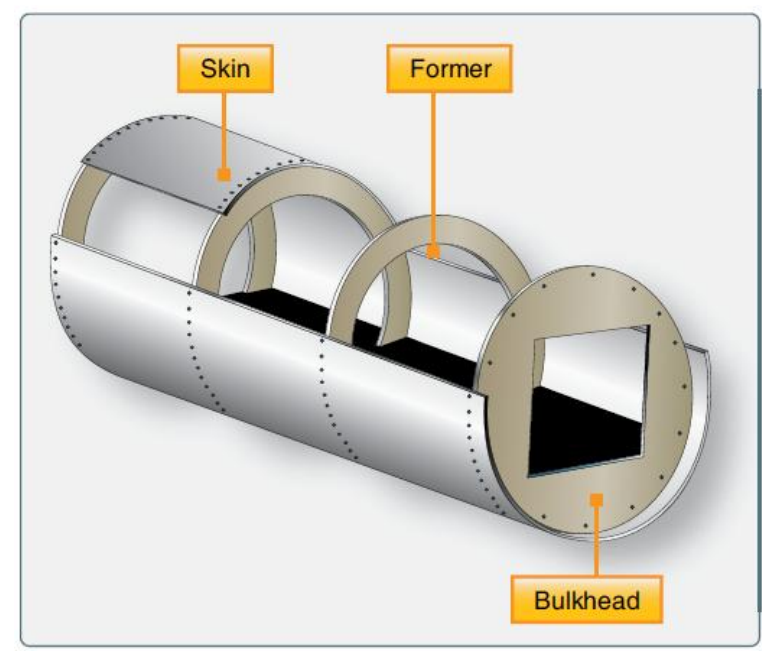

Fig-3: An airframe using monocoque construction.

\subsubsection{Semimonocoque}

To overcome the strength/weight problem of monocoque construction, a modification called Semimonocoque construction was developed. It also consists of frame assemblies, bulkheads, and formers as used in the monocoque.

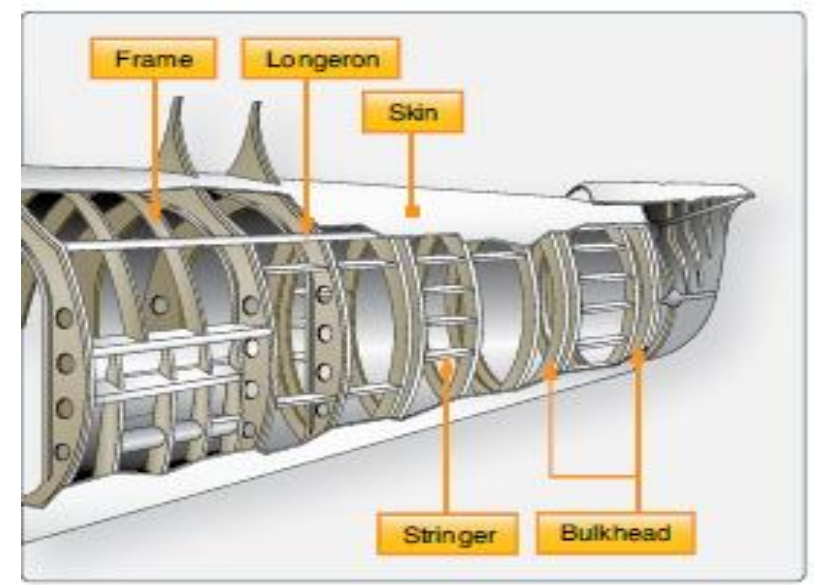

Fig-4: The most common airframe construction is Semimonocoque.

\subsection{Rear Fuselage/Tail Cone Section/Empennage}

The empennage also known as the tail or tail assembly [Figure 1.5], of most aircraft gives stability to the aircraft, in a similar way to the feathers on an arrow the term derives from the French for this. Most aircraft feature empennage incorporating vertical and horizontal stabilizing surfaces which stabilize the flight dynamics of pitch and yaw, as well as housing control surfaces.

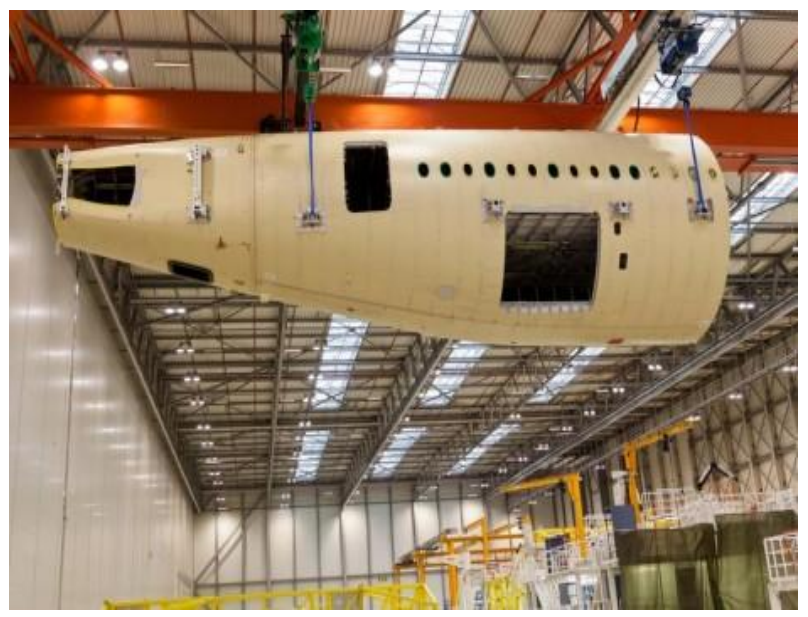

Fig-5: Rear fuselage/tail cone section

\section{OBJECTIVES}

\subsection{Objective}

Identification of stress location in a structure, due to air load acting on the horizontal tail gets transfer to rear fuselage, identification of critical locations for crack initiation at stress location and to ensure the safety of Rear fuselage with cargo cutout.

\subsection{Methodology}

- $\quad$ Modeling rear fuselage with cutout using CATIA V5 R18.

- Stress analysis using software package "MSC.PATRAN" and "MSC.NASTRAN" for identification of high stress region. 
- $\quad$ S-N curve based miner's rule will be used for fatigue life estimation calculation.

\section{CATIA MODEL}

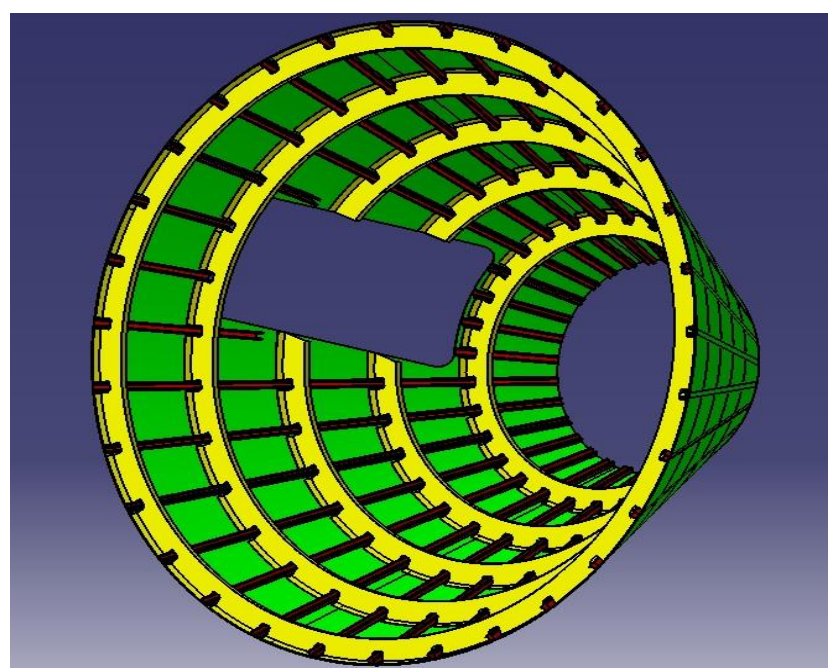

Fig-6: CATIA MODEL

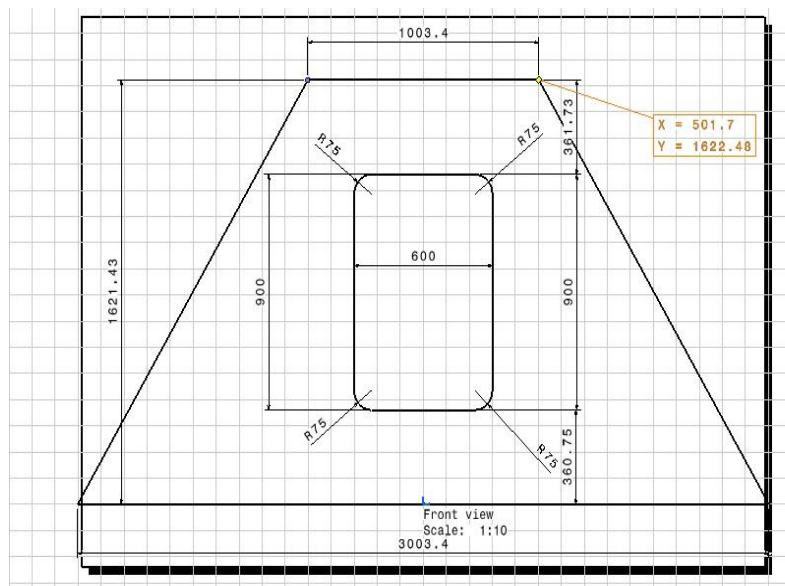

Fig-7: Fuselage geometry

\section{FINITE ELEMENT MODEL}

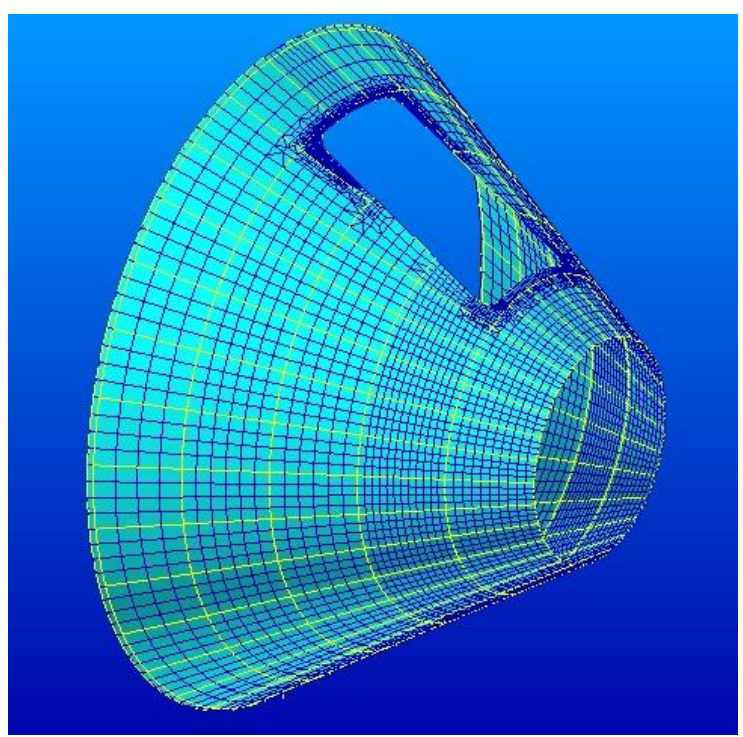

Fig-8: Finite element model

\section{Skin}

The skin is outer most component of an aircraft which consist of lateral members like Bulkheads, and longitudinal members like Longerons. Skin consist of cutout maximum stress concentration will be near to cutout, therefore for stress analysis the Skin is considered as two dimensional. Mesh detail of the Skin is shown in table.

\section{Bulkheads}

It is considered as one dimensional element for global analysis, depending on the stress result bulkhead will be considered as two dimensional for local analysis is required.

\section{Longerons}

It is considered as one dimensional element for global analysis, depending on the stress result bulkhead will be considered as two dimensional for local analysis is required.

After meshing, all the component of the rear fuselage are assembled to each other as

\subsection{Loads Cases and Boundary Conditions on Rear Fuselage}

Boundary condition is application of force and constraint. The ends of finite element model fuselage are constrained in both translational and rotational degree of freedom. A uniformly distributed load is applied on each bulked in load case 1 , here the loads of cargo, vertical tail, and rear fuselage is applied on to rear fuselage.

\section{Load detail}

$\begin{array}{ll}\text { Cargo load } & 600 \mathrm{~kg} \\ \text { Horizontal load } & 900 \mathrm{Kg} \\ \text { Vertical load } & 170 \mathrm{~kg} \\ \text { Movement } & 810000 \mathrm{~kg}-\mathrm{mm} \\ \text { Rear fuselage } & 160 \mathrm{~kg}\end{array}$

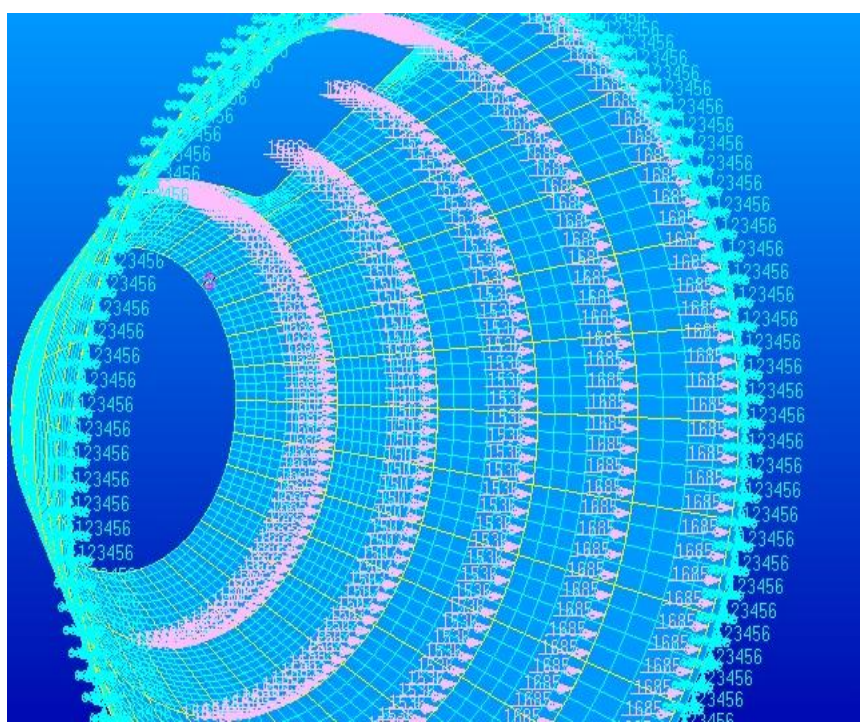

Fig-9: Load and boundary conditions 


\subsection{Displacement Contour of the Rear Fuselage}

The shows the displacement contour of rear fuselage. Displacement contour increases from fixed end to loading end and it is shown by different colors fringes with blue color showing minimum magnitude of displacement while red color showing maximum magnitude of displacement as $0.756 \mathrm{~mm}$.

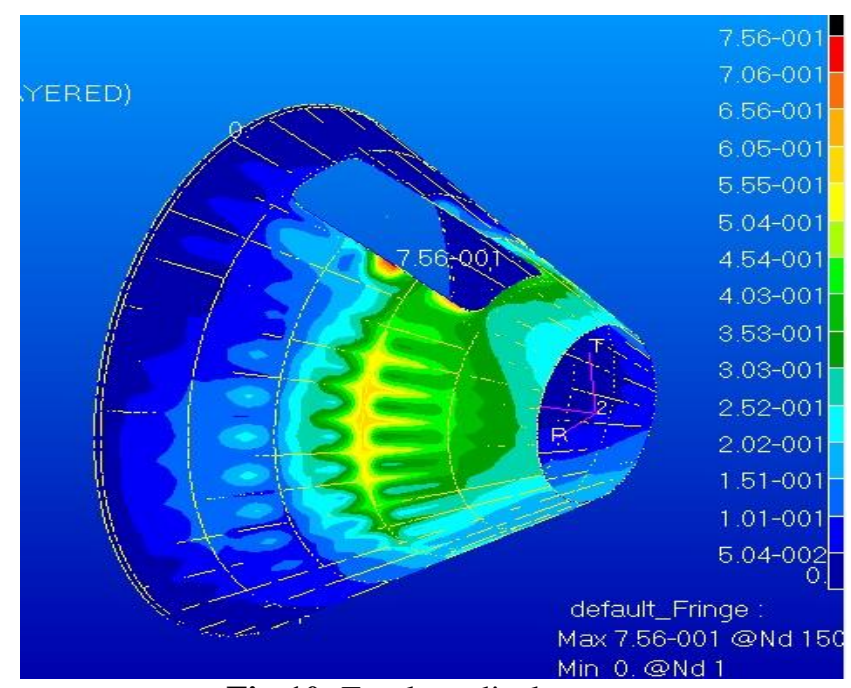

Fig-10: Fuselage displacemet

\subsection{Stress Contour of the Rear Fuselage}
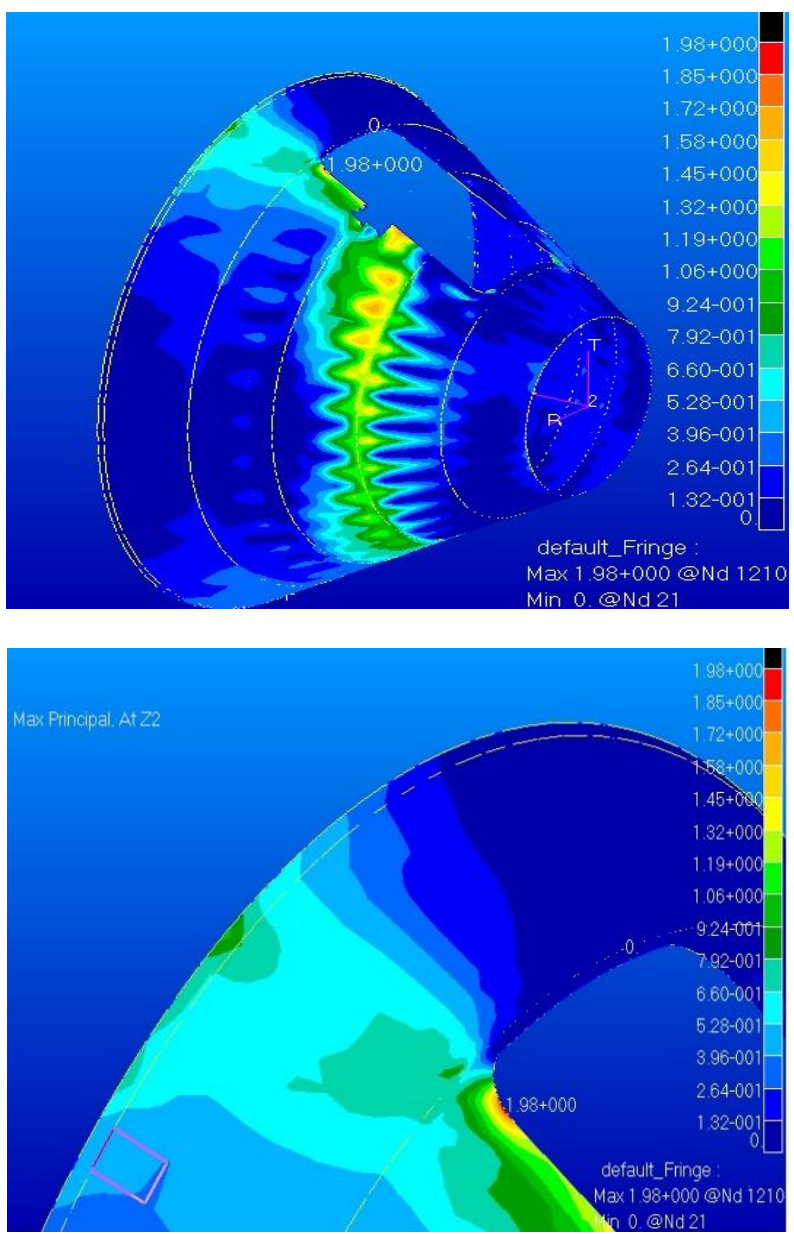

Fig-11: Stress contour for skin with a close up view
The magnitude of maximum principle stress is 1.98 $\mathrm{Kg} / \mathrm{mm}^{2}=19.42 \mathrm{~N} / \mathrm{mm}^{2}$ is observed from the Fig-11. The maximum stress locations are the probable locations for crack initiation. Invariably these locations will be at cut-out corners and rivet locations in the skin. Since in global modal entire structure is not represented as it is, for the sake of time reduction bulkhead and longerons is considered as one dimensional and skin as two dimensional, hence the stress result obtained from global cannot be considered as final stress results, so a panel with cut-out is considered for local analysis, in which skin, bulkhead and longerons are considered as two dimensional for detailed study of stress distribution at the cut-out corner.

\subsection{Local Stress Analysis of Panel with Cargo Door}

\section{Cutout}

Skin consist of cutout, the maximum stress concentration will be near to cutout corner, therefore for element near to cut-out corner is fine meshed and around it coarse mesh is maintained

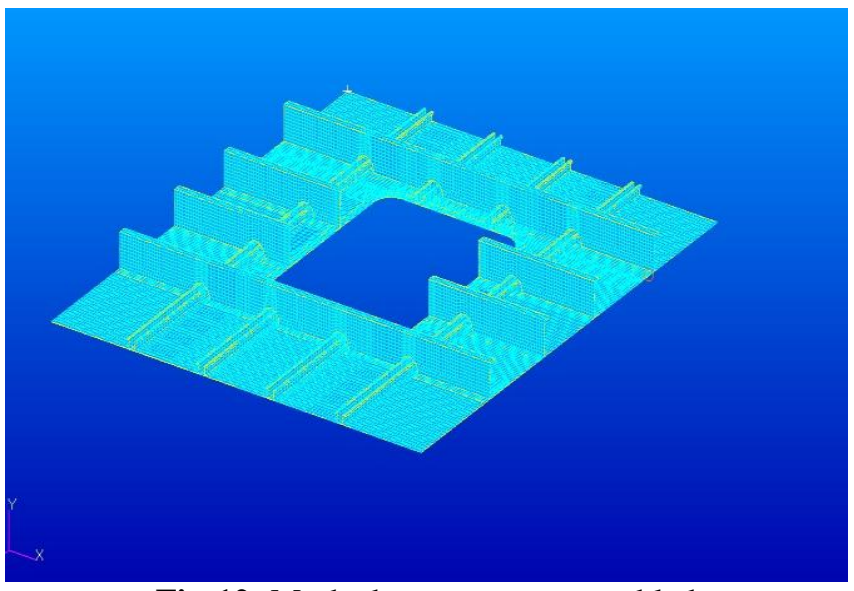

Fig-12: Meshed component assembled

\subsection{Loads Cases and Boundary Conditions on Rear}

\section{Fuselage}

Boundary condition is application of force and constraint. The ends of finite element model fuselage are constrained in both translational and rotational degree of freedom. Depending on the deformation of the local model all the element are, fixed in $\mathrm{Y}$ axis in order to constrain deformation in $\mathrm{Y}$ direction. A uniformly distributed load is applied on each bulked in load case 1, here the loads of cargo, vertical tail, and rear fuselage is applied.

\section{Displacement Detail}

1. Translation in $\mathrm{X}, \mathrm{Y}, \mathrm{Z}$ are constrained [0 00 0 $]$

2. Rotation in $\mathrm{X}, \mathrm{Y}, \mathrm{Z}$ are constrained [0 00 0 0$]$

3. Deformation in $\mathrm{Y}$ axis constrained [- 0 - ]

\section{Load Detail}

Since the load which was applied in the global analysis cannot be applied to the local analysis, as there is change in 
geometry, hence the average of elemental stress values near cut-out in rear fuselage of global model is considered. The average stress value obtained is $0.1468 \mathrm{~kg} / \mathrm{mm}^{2}$ from global, using the formula (4.1) load is calculated, and applied to structure

$$
\sigma=\frac{p}{A}
$$

Where

$\sigma$ - Average stress

P- Applied load

A- Cross section area

\section{Load Details}

- $\quad$ Skin

$$
0.1468=\frac{p}{3104}=456 \mathrm{~kg}
$$

- Longerons

$$
0.1468=\frac{p}{188}=27.588 \mathbf{~ k g}
$$

In local analysis, loads are applied on to longerons and skin, in order to achieve the same stress value, as in global model analysis stress (i.e. $1.8 \mathrm{~kg} / \mathrm{mm}^{2}$ ) ), 2.5 times load is applied on longerons and skin to obtain the same stress value of 1.8 $\mathrm{kg} / \mathrm{mm}^{2}$.

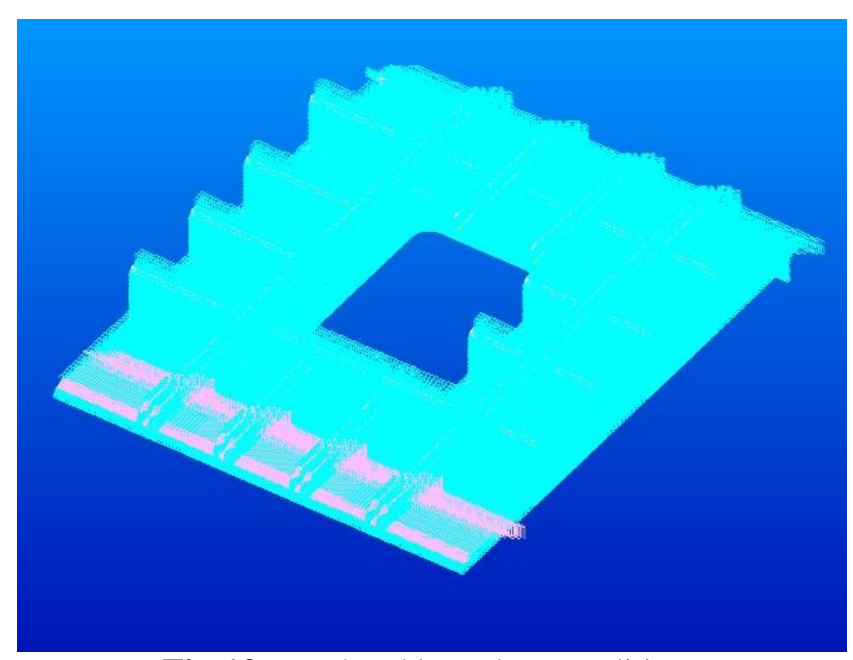

Fig-13: Load and boundary conditions

\subsection{Displacement Contour of the Rear Fuselage}

The Fig-14 shows the displacement contour of rear fuselage. Displacement contour increases from fixed end to loading end and it is shown by different colors fringes with blue color showing minimum magnitude of displacement while red color showing maximum magnitude of displacement as $0.195 \mathrm{~mm}$.

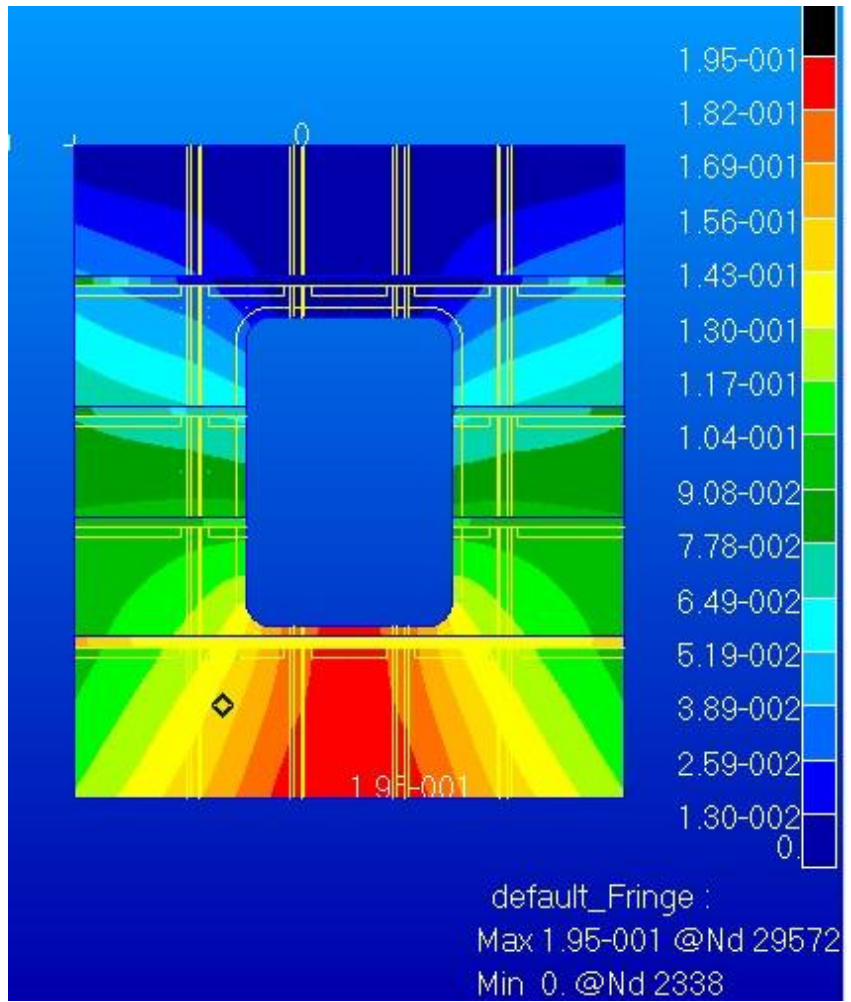

Fig-14: Displacement Contour of the rear fuselage

\subsection{Stress Contour of the Rear Fuselage}

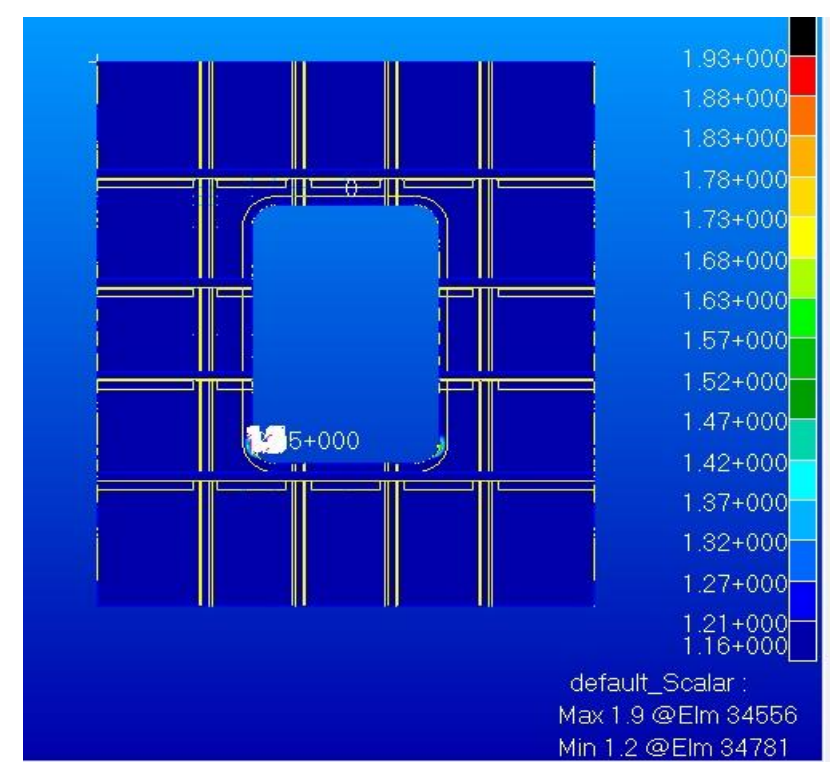




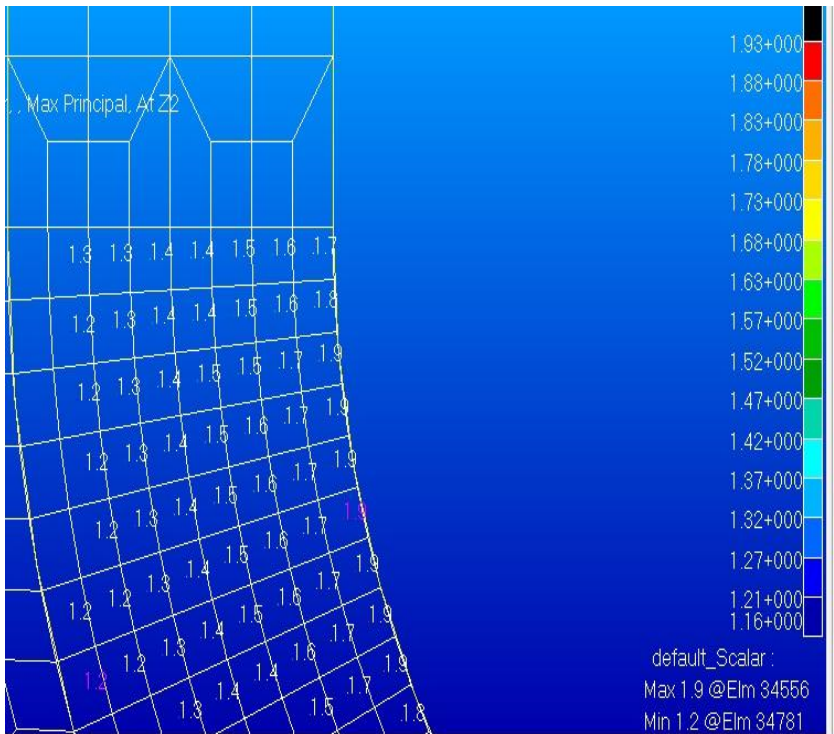

Fig-15 Stress contour for skin with a close up view

Fig-15 shows the stress contour on the skin from stiffened panel analysis results. It is clear that the maximum stress on skin is at the rivet location where the rivets are used to fasten the bulkheads, longerons and skin. The magnitude of maximum tensile stress is $1.9 \mathrm{Kg} / \mathrm{mm}^{2}=19.46 \mathrm{~N} / \mathrm{mm}^{2}$ in the loading direction can be observed from the Fig-15. The maximum stress locations are the probable locations for crack initiation. Invariably these locations will be at rivet locations in the skin. Representation of layered structure is important in identifying critical stress locations, integral representation will miss lead as for as critical locations are concerned.

\section{FATIGUE}

From the stress analysis of the rear fuselage the maximum tensile stress location is identified. A fatigue crack will always initiate from the location of maximum tensile stress. From the stress analysis it is found that such a location is at one of the rivet hole. A typical flight load spectrum is considered for the fatigue analysis of the vertical tail skin joint. A damage tolerance design criteria and stress-life approach has been adopted for conducting a fatigue analysis. For performing fatigue calculations constant amplitude loading is preferred. In this problem variable amplitude loads will be acting but by converting them to groups of constant amplitude loading in their respective frequency. If loading is constant amplitude, than its represents the numbers of cycles until the part will failure due to fatigue. Calculation of fatigue life to crack initiation is carried out by using Miner's Rule. The various correction factors are considered in the calculation of fatigue cycles, they are:

For surface roughness $\left(\mathrm{e}_{\mathrm{sr}}\right)-0.8$

For type of loading $\left(\mathrm{e}_{1}\right)-1$

For reliability design $\left(\mathrm{e}_{\mathrm{r}}\right)-0.897$
Fatigue calculation is done by simplifying the variable spectrum loading into blocks of loading which is shown in the Table 1.

Table 1: Load ranges during its entire life

\begin{tabular}{|l|l|}
\hline Number of cycles & Range of "g" loads \\
\hline 15000.00 & 0.5 to $0.75 \mathrm{~g}$ \\
\hline 11000.00 & 0.75 to $1 \mathrm{~g}$ \\
\hline 10000.00 & 1 to $1.25 \mathrm{~g}$ \\
\hline 8000.00 & 1.25 to $1.5 \mathrm{~g}$ \\
\hline 20.00 & $1.75 \mathrm{~g}$ \\
\hline 1.00 & $2 \mathrm{~g}$ \\
\hline 100.00 & $-0.5 \mathrm{~g}$ to $1.5 \mathrm{~g}$ \\
\hline
\end{tabular}

In the above mentioned cycles shown the term ' $\mathrm{g}$ ' corresponds to the acceleration due to gravity. The load corresponding to $1 \mathrm{~g}$ is equivalent to the weight of the aircraft. Fatigue analysis is carried out until the crack becomes critical. We know that the crack becomes critical. When the stress intensity factor becomes equal to the fracture toughness of the material used. The fracture Toughness of the material aluminum alloy 2024-T351 is $98.8 \mathrm{MPa} \sqrt{ }$. So when the stress intensity factor becomes equal to the fracture toughness we can say that the crack becomes critical and the materials get fail. By knowing the critical crack length we can predict for how many number of flying hours the material is safe.

For different stress amplitudes the number of cycles to failure is obtained. From typical constant life diagram for un-notched fatigue behavior of 2024-T351 Aluminum alloy chart as shown in [Figure 5.3]. The reference test condition $\mathrm{R}=0$ used to obtain fatigue properties. For this condition $\sigma_{\min }=0$ is called 'pulsating tension' under constant amplitude loading. According to Palmgren-miner's rule the stress amplitude is linearly proportional to the ratio of number of operation cycles to the number of cycles to failure from the graph gives the damage accumulated.

From Miner's equation,

$$
\Sigma \mathrm{N}_{\mathrm{i}} / \mathrm{N}_{\mathrm{f}}=\mathrm{C} \text {--------- }(5.1)
$$

Where

$\mathrm{N}_{\mathrm{i}}=$ Applied number of cycles

$\mathrm{N}_{\mathrm{f}}=$ number of cycles to failure

$\mathrm{C}=$ constant equal to 1

\section{Damage accumulated for $\mathrm{N}_{\mathrm{i}}=\mathbf{1 2 0 0 0}$ cycles}

$$
\begin{aligned}
\mathrm{d}_{1} & =\mathrm{N}_{\mathrm{i}} / \mathrm{N}_{\mathrm{f}^{-}} \\
& =12000 / 10 \mathrm{E}+7
\end{aligned}
$$

$\mathbf{d}_{1}=\mathbf{0 . 0 0 1 2}$ 
Table 2: Damage Accumulated in the Rear fuselage with cut-out

\begin{tabular}{|l|l|l|l|l|l|}
\hline $\begin{array}{l}\text { Cycle } \\
\mathbf{s}\left(\mathbf{N}_{\mathbf{i}}\right)\end{array}$ & $\begin{array}{l}\text { Range of } \\
\text { 'g' }\end{array}$ & $\begin{array}{l}\text { Ampl } \\
\text { itude } \\
\text { Stres } \\
\mathbf{s}\left(\boldsymbol{\sigma}_{\mathbf{a}}\right) \\
\text { in } \\
\text { Ksi }\end{array}$ & $\begin{array}{l}\text { Mean } \\
\text { Stress } \\
\left(\boldsymbol{\sigma}_{\mathrm{m}}\right) \\
\text { in Ksi }\end{array}$ & $\begin{array}{l}\text { Stres } \\
\mathbf{S} \\
\text { Rati } \\
\mathbf{o}(\mathbf{R})\end{array}$ & $\begin{array}{l}\text { Damage } \\
\text { Accumul } \\
\text { ated }\end{array}$ \\
\hline 15000 & $\begin{array}{l}0.5 \text { to } \\
0.75 \mathrm{~g}\end{array}$ & 0.56 & 2.82 & 0.66 & $1.50 \mathrm{E}-03$ \\
\hline 11000 & 0.75 to $1 \mathrm{~g}$ & 0.56 & 3.94 & 0.75 & $1.10 \mathrm{E}-03$ \\
\hline 10000 & 1 to $1.25 \mathrm{~g}$ & 0.56 & 5.07 & 0.8 & $1.00 \mathrm{E}-03$ \\
\hline 8000 & $\begin{array}{l}1.25 \quad \text { to } \\
1.5 \mathrm{~g}\end{array}$ & 0.56 & 6.20 & 0.83 & $8.00 \mathrm{E}-04$ \\
\hline 20 & 0 to $1.75 \mathrm{~g}$ & 3.94 & 3.94 & 0 & $2.00 \mathrm{E}-06$ \\
\hline 1 & 0 to $2 \mathrm{~g}$ & 4.51 & 4.51 & 0 & $1.00 \mathrm{E}-07$ \\
\hline 100 & $\begin{array}{l}-0.5 \mathrm{~g} \\
\text { to1.5g }\end{array}$ & 4.51 & 2.25 & -0.33 & $1.00 \mathrm{E}-05$ \\
\hline
\end{tabular}

Damage accumulated is as shown in the [Table 2]. Results gives the structure has an infinite life even though we were getting some damage, calculated using a standard S-N curve for aluminum alloy $2024 \mathrm{~T} 351$ as show in the [Fig-16]. This $\mathrm{S}-\mathrm{N}$ curve gives the approximate damage not the accurate one. This curve is taken from Bruhn analysis and design of flight vehicles book. From results of fatigue analysis for different pressure cycles got the damage fraction is less than unity i.e. 1.5E-03+1.10E-03+1E-03+8E-04+2E-06+1E07+1E-05=0.000441. According to Palmgren-Miner linear damage rule when the damage fraction is less than unity the material is safe, often satisfactorily for failure is predicted. The damage at which failure is expected to occurs when the damage fraction is equal to 1 .

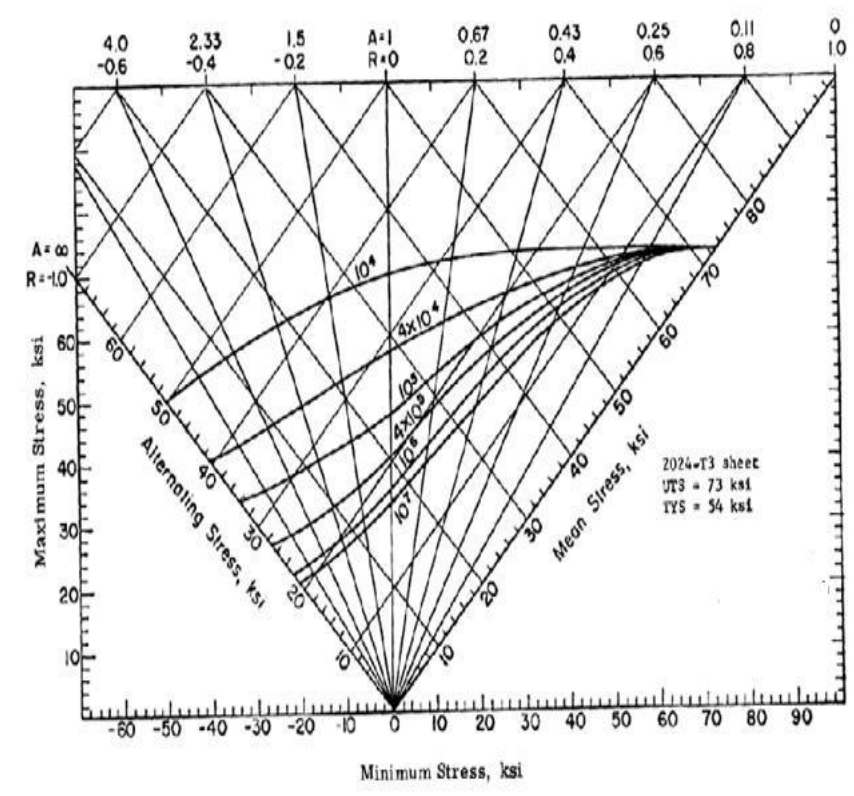

Fig-16: S-N curve for Aluminum alloy 2024 T351

\section{CONCLUSION}

1. Rear fuselage with cargo door cutout was analyzed by considering fuselage inertia load along with HT \& VT loads.

2. As expected maximum stress was obtained near corner of cutout region.

3. Finite element model approach was used for stress analysis of component.

4. Maximum tensile stress obtained from global analysis is $1.8 \mathrm{~kg} / \mathrm{mm}^{2}$ or $17.65 \mathrm{~N} / \mathrm{mm}^{2}$.

5. A local analysis was carried out by considering a panel with cargo door cutout, refinement of mesh was carried out to obtain the accurate stress magnitude near cutout region.

6. Maximum tensile stress obtained from local analysis is $1.9 \mathrm{~kg} / \mathrm{mm}^{2}$ or $19.65 \mathrm{~N} / \mathrm{mm}^{2}$.

7. There are tiny holes around the large cargo door cutout in actual structure. The stress concentration factor because of the small hole was considered to obtain the maximum tensile stress.

8. Maximum tensile stress by considering stress concentration factor was $93.195 \mathrm{~N} / \mathrm{mm}^{2}$.

9. The structure is expected to experience fluctuating loads during flight. Therefore fatigue crack may get initiated near the maximum tensile stress location.

10. The maximum tensile stress obtained from local analysis is used as the input in the fatigue damage calculations.

11. A typical transport aircraft load spectrum is used for fatigue damage calculations.

12. MINER's rule is adapted for calculation of linear damage accumulation.

13. Damage accumulation for the given load spectrum is calculated by using S-N curve of respective material.

14. Fatigue life of crack initiation for the given load spectrum is 22,222 flying hours.

\section{REFERENCES}

[1]. Sartaj Patel, Mahesha. K, Harish.E.R.M, "Stress analysis of a fuel access cutout of the bottom skin of a transport aircraft" IJIRSET, vol. 2, issue 7, July 2013.

[2]. Adarsh Adeppa, Dr. M. S. Patil, K. E. Girish, "Stress Analysis and Fatigue Life Prediction for Splice Joint in an Aircraft Fuselage through an FEM Approach" ", IJIRSET, volume 1, issue 4, April 2012.

[3]. S Sarath1, Jason Cherian Issac1 and K E Girish, "Analysis of the wing box with spliced skin and estimation of the fatigue life for the wing box", IJMERR, Vol. 2, No. 2, April 2013.

[4]. Pir M Toor, "On Damage Tolerance Design of Fuselage Structure (Longitudinal Crack)", engineering fracture mechanic, Vol 24. No 6, pp915-927.1986.

[5]. Schijve Jaap, "Fatigue damage in aircraft structures, not wanted, but tolerated"? Delft University of Technology, Faculty of Aerospace Engineering Kluyverweg 1, 2629 HS, the Netherlands.

[6]. Saleh Yazdani, G. H. Rahimi, Mehdi Ghanbari "Experimental and numerical stress analysis of FML plates with cutouts under in-plane loading", Mechanical 
Engineering Department, Tarbiat Modares University, Tehran, Iran, ISSN 1392 - 1207. MECHANIKA. 2013 Volume 19(2): 128-134.

[7]. Venkatesha B K, Suresh B S2 \& Girish K E “Analytical Evaluation of Fatigue Crack Arrest Capability in Fuselage of Large Transport Aircraft". R.V.College of Engineering, Bangalore, India 3 Bangalore Aircraft Industries Ltd, Bangalore, ISSN (Print): 2319-3182, Volume-1, Issue-1, 2012.

[8]. P. M. S. T. de Castro, S. M. O.Tavares, V. RichterTrummer, "Damage tolerance of aircraft panels", Faculdade de Engenharia da Universidade do Porto, IDMEC-FEUP, Porto, Portugal.

[9]. Madhura B M, N.G.S. Udupa, Rajanna S, "Damage tolerance evaluation of wing in presence of large landing gear cutout through stress analysis Using FEM", IJRET, Volume: 03 Issue: 01, Jan-2014.

[10]. G.I. Nesterenko, B.G. Nesterenko, "Ensuring structural damage tolerance of Russian aircraft", International Journal of Fatigue 31 (2009) 1054-1061.

[11]. A.Rukesh Reddy, P. Ramesh, B. Siddeswara rao , "Stress Analysis of Splice Joint of the Aircraft Bottom Wing Skin by Finite Element Method", International Journal of Computational Engineering Research, Vol, 03,Issue, 11.

[12]. Campbell G. S. and Lahey R., "A survey of serious aircraft accidents involving fatigue fracture", Int. J. of Fatigue, Vol. 6 No. 1 January 1984, ISBN 01421123/84/010025-06.

[13]. Buehrle Ralph D, Fleming Gary A. and Pappa Richard S., "Finite element model development and validation for aircraft fuselage structures", 18th International Modal Analysis Conference San Antonio, Texas February 7-10, 2000.

[14]. Goranson Ulf G., "Fatigue issues in aircraft maintenance and repairs", ElsevierInt. J. for Fatigue Vol. 20, No. 6, Pages 413-431, 1997.

[15]. C.M. Sonsino, "Course of SN-curves especially in the high-cycle fatigue regime with regard to component design and safety", Int. J. of Fatigue 2007.

[16]. Johannessona Par., Svenssona T., De Mare Jacques, "Fatigue life prediction basedon variable amplitude testsmethodology", Int. J. of Fatigue, vol. 27, Pages 954-965. (C) 2005 Elsevier Ltd.

[17]. Mustang Citation, "Operating manual chapter-12 pressurization”, 510 OM-00 12-1, Pages 12-22.

[18]. Aerospace medical association, aviation safety committee, civil aviation subcommittee, "Cabin cruising altitudes for regular transport aircraft", Aviatspace environ med 2008; 79:433-9.

[19]. Abraham Brot "development of fatigue life regulations based on lessons learned from several aircraft accidents" Presented to the Israel Annual Conference on Aerospace Sciences, 2006, Engineering Division, Israel Aircraft Industries, Ben-Gurion Airport, Israel.

\section{BIOGRAPHIES}

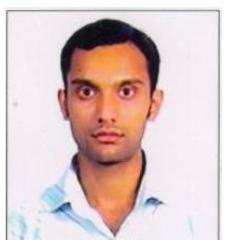

Mr. .Chetan. B. S obtained his Bachelor of Engineering in SKIT, Bangalore, Karnataka in 2012 and is Post graduate in M.Tech (Computer Aided Engineering), At VTU-CPGS, Bangalore.

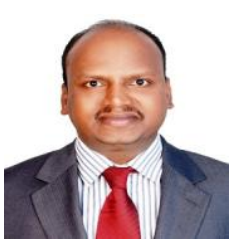

Mr. Narayana Swamy G, Asst. Professor, Dept. of CAE, VTU-CPGS, Muddenahalli

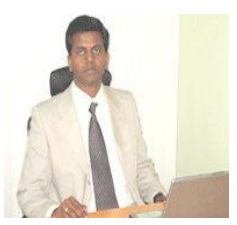

Ex-scientist at National Aerospace laboratories, Mechanical engineering from Adichunchanagiri institute of technology, Chikmagalur. Eleven years of experience in the field of aircraft structural testing and analysis at structural integrity division of NAL. 